\title{
Comprehensive Design of an Earthing System for Broadlands Hydropower Station Switchyard
}

\section{B.A.S.R. Pradeep, Lalith A. Samaliarachchi and Anuradha Mudannayake}

\begin{abstract}
Broadlands Hydropower Project (BHP) harnesses the last hydropower potential of Kehelgamu-Maskeli Oya rivers with an installed capacity of 35 MW and 126 GWh annual energy generation. Excavation of the powerhouse switchyard site exposed to a bedrock formation with highly weathered granitic gneiss beneath a thin layer of scum soil top, resulting in an irregular high soil resistivity profile. Therefore, the main purpose of this research is to design a safe and effective grounding system for the switchyard of BHP, which can carry fault current into the ground without exceeding tolerable ground potential rise, ensuring the desired operation of protective \& control devices so that not to endanger human \& equipment. Owing to the nature of non-uniform high soil resistivity and limited land space for extension, this has become a great challenge. Research used two approaches, guidelines of conventional IEEE 80-2000 standards and Finite Element Method (FEM). Initially, resistivity measurement was conducted covering the entire area of concern. A soil model was prepared using orthodox horizontally stratified two-layer soil model using Sunde's graphical technique based on measured data. Then the grounding grid was designed adhering to guidelines given in IEEE 80:2000 standard and observed high overall grid resistance, eventually exceeding the tolerable step and touch potential levels. Thereafter a soil model was prepared based on FEM which facilitates plot of accurate and smooth surface voltage distribution over the entire switchyard area. Applying fault current to these discrete finite elements and based on the first principle of Kirchhoff's current distribution balance, the localized voltage distribution has been developed for the entire area and plotted using a self-developed MATLAB computer program. FEM model can trace the points where the touch and step potentials exceed safe limits in two-dimensional stratified grid, estimation of voltage gradients at boundary areas, which all are unable to track using conventional IEEE method. Accuracy of the model can further be increased by reducing the size of the soil element. Finally, several sensitivity studies were conducted so as to optimize the BHP switchyard grid design ensuring safe grid operation.
\end{abstract}

Keywords: Ground Potential Rise, Touch Potential, Step Potential, Soil Resistivity, IEEE Standard, FEM Model

\section{Broadlands Hydropower Project}

\subsection{Introduction}

Broadlands Hydropower Project (BHP) harnesses the last hydropower potential of Laxapana complex located in the downstream of Kelani river basin. The main dam and weir sites of the BHP is located in Pallewaththa and Polpitiya areas respectively in the Central province, whereas the power station site is located in Kalukohuthenna, Kithulgala area, belonging to Sabaragamuwa province. Powerhouse site is bordering Kelani river from North, forest reservation from East and South, and Kartaranoya from West. The total working area is constraint to about 1.6 ha. According to the basic design layout, about $34 \%$ of land covered under the powerhouse construction and the land extent of the switchyard approximated to $20 \%$ of the total land use. Tailrace construction occupies an estimated $46 \%$ of land [2]. Excavation of powerhouse and the tailrace went down to the bedrock where the earth mat laid beneath concrete and the switchyard consists mainly of weathered rock/soil mix geology.

\subsection{Identification of the Existing Problems in BHP Earthing}

The safety of a person depends on preventing the critical amount of shock energy being absorbed by the human body before the fault is cleared and the system is de-energized. Maximum driving point voltage of any accidental circuit should not exceed the safety limits which basically depends on the grid

Mr. B.A.S.R. Pradeep, B.Tech. Eng. (Hons), The Open

University of Sri Lanka, Electrical Superintendent,

Lakvijaya complex, Ceylon Electricity Board.

Email:samee0215@yahoo.com

(iD) http://orcid.org/0000-0003-0048-487X

Eng. Lalith A. Samaliarachchi, C. Eng., MIE(SL),

MIEE(UK), B.Sc. Eng. (Hons) (Moratuwa), M. Eng. (AIT),

Senior Lecturer, Department of Electrical \& Computer

Engineering, The Open University of Sri Lanka

Email:lasam@ou.ac.lk

(iD http://orcid.org/0000-0001-9447-4757

Eng. Anuradha Mudannayake, C. Eng., MIE(SL)

MIET(UK), B.Tech. Eng. (Hons) (OUSL), M.Sc. Eng.

(Moratuwa), M.BA (IGNOU), Project Engineer, Broadlands

Project, Ceylon Electricity Board.

Email:cebgen@hotmail.com

ii http://orcid.org/0000-0001-8384-6535 
earth resistance. Designing of low resistive earthing system in BHP powerhouse and tailrace structures was found extremely difficult where excavations were done down to bed rock having high soil resistivity, and further grid expansion was not possible owing to geological constraints. Also, no appreciable buffer zone was possible for powerhouse construction area in which public roads are located adjacent to earth mat boundaries.

The performance analysis of an earthing system essentially consists of determination of earth resistance and earth surface potential distribution owing to the dissipated current during an earth fault [1]. In here, BHP generation switchyard would be connected to the national grid at $132 \mathrm{kV}$ level and hence counts for high fault currents. Therefore, proper design of an earthing system is a must requirement to safeguard against human and property damages.

\subsection{Objectives}

Primary objectives of this research study are to:

- Conduct, soil resistivity survey for the proposed switchyard area and prepare a soil resistivity profile both under wet condition as well as dry condition.

- Model, soil resistivity using:

- Conventional Sunde's method

- Distributed parameter method run on basic principles

- Design, an earthing system based on IEEE empirical formulas.

- Develop, discrete earth design model based on FEM using basic principles.

- Evaluate, surface potential distribution, touch potential distribution, step potential distribution and grid resistance.

- Conduct, sensitivity studies.

\section{Literature Survey}

In a ground fault condition, the flow of current to earth will produce potential gradients within and around the earth rod or mat. Unless proper precautions are taken in design, the maximum potential gradients along the earth's surface may be of sufficient magnitude during ground fault conditions endangering a person in the area. A person can experience an electric shock as a result of this potential gradient, and it refers to as step potential. Moreover, dangerous voltages may develop between grounded structures or equipment frames and the nearby earth. This can also make an electric current to flow when a person touches both the structure and earth at the same time and this refers to as the touch potential [3]. A proper earthing system should be capable of avoiding risky step and touch potentials and be able to safeguard human and machine under worse possible electric fault conditions.

Hence sound design of a safe grid substation earthing system should mainly consist of:

1. Detailed soil modelling

2. Earthing conductor configuration design

3. Post evaluation of the designed system and redesign if required

Earthing system design can mainly be analysed using two common mathematical approaches:

- Conventional method: Mainly in accordance with the guidelines given in IEEE Std. 80

- Numerical techniques: Under this category various mathematical approaches are possible such as finite difference method (FDM), finite element method (FEM), charge simulation method (CSM), boundary element method (BEM) and hybrid or combinations of these methods, like FEM/BEM method etc.

Differences and improvements of various numerical analysis methods mainly lie in their calculation accuracy, complexity of calculation, computing time and the occupied memory size of computer when calculating the resistance coefficient and leakage current distribution on the grounding system [1].

\section{Methodology}

Design methodologies of the research work consist of two main categories and two subcategories and they are as follows:

- $\quad$ Soil Modelling using:

- Conventional two-layer Sunde's graphical method

- Discrete soil resistivity model

- Design of earthing system based on:

- Conventional IEEE method

○ Finite Element Method (FEM)

The most commonly used soil resistivity models are the uniform soil model and the twolayer soil model. A more accurate representation of the actual soil conditions can be obtained using two-layer model [5]. Under discrete soil resistivity modelling, the area that has been taken into consideration for the earthing system design should be thoroughly investigated for 3D resistivity profiling. Shorter 
the distance between points of measurement, higher the depth of penetration leading to higher accuracy of the model. Using measured apparent soil resistivity values of top layer and layers up to $8 \mathrm{~m}$ depth, conceptual framework is formulated. Thereafter, desired discrete point characteristics are calculated using mathematical interpolation using MATLAB coding. A cloud of points with respective resistivity values for each element are calculated for the entire area of study.

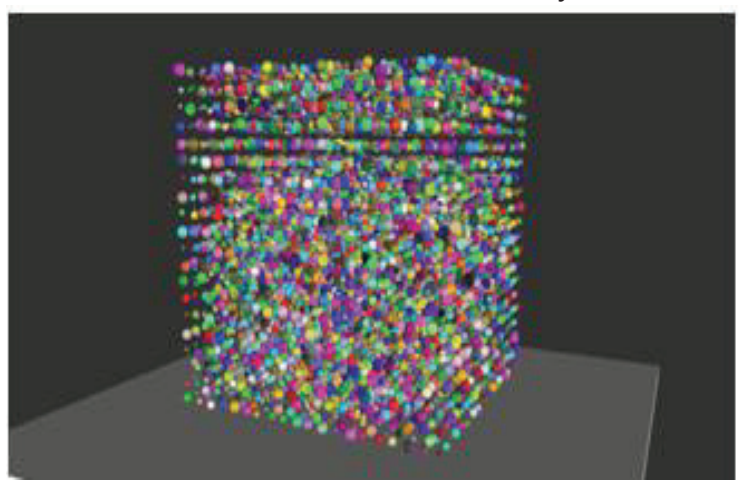

\section{Figure 1 - Conceptual view of discrete resistivity model}

Under first earthing design approach, "IEEE80-2000 IEEE Guide for Safety in AC Substation Grounding" design methodology is referred, and the flow chart of the basic guidelines are illustrated in Appendix A, FigureA1.

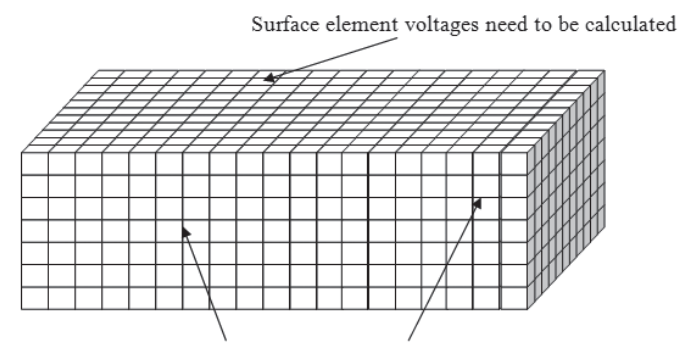

Boundary element voltage is assumed to decaying to zero at far end

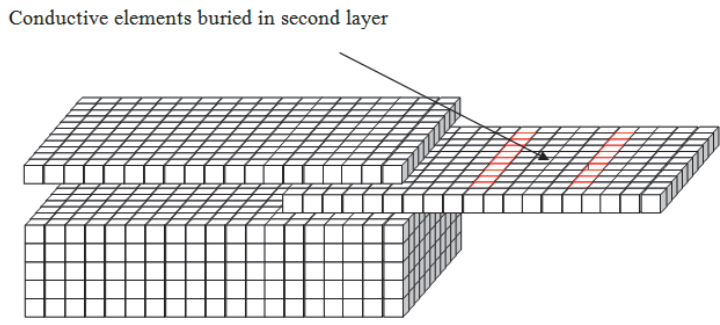

Figure 2 - Elemental view of FEM model

Under FEM, earth can be represented by a pure resistance [5] and hence $3 \mathrm{D}$ soil region of switchyard is modelled as a combination of large number of small pure resistive elements connected with other elements through their intermediate surfaces. If the soil element happens to be the top layer, it is connected with 5 other elements surrounding it, otherwise it is connected with 6 other elements (except boundary elements) as shown in Figure 2. Also, grounding conductors and rods are divided into small elements and these conductive elements are considered as voltage elements because of ground potential rise. Owing to these voltage elements, leakage currents passed to the other soil elements through their interconnected surfaces, hence leakage current distribution throughout the region is according to Kirchhoff law.

As a result of the leakage currents distribution, surface voltage distribution builds up. Surface voltage distribution is the main figure of the earthing system design process because it can be used to evaluate other critical design parameters such as step voltage and touch voltage.

Further analysis of surface voltage distribution can be extended by changing conductor space and rods of earthing systems until it satisfies the step, touch and mesh voltage criteria as given in IEEE standards. A simplified working algorithm of the MATLAB programme is as attached in Appendix B, Figure B1.

\section{Soil modelling}

4.1 Two-layer soil model using Sunde's graph Table 1 shows the measured resistivity values using Wenner method for about 10 points distributed over Broadlands switchyard.

Table 1 - Measured resistivity value

\begin{tabular}{|c|c|c|c|c|c|c|c|c|c|c|c|}
\hline \multirow{2}{*}{$\begin{array}{l}\text { Probe } \\
\text { Space } \\
\text { (m) }\end{array}$} & \multicolumn{10}{|c|}{ Point No. } & \multirow{2}{*}{$\begin{array}{l}\text { Avg. } \\
(\Omega \mathrm{m})\end{array}$} \\
\hline & 01 & 02 & 03 & 04 & 05 & 06 & 07 & 08 & 09 & 10 & \\
\hline 3 & 6260 & 4310 & 3203 & 2525 & 3052 & 2883 & 3090 & 2807 & 3316 & 3090 & 3454 \\
\hline 4 & 5641 & 5243 & 2893 & 2200 & 2988 & 2564 & 3133 & 2569 & 3116 & 3523 & 2823 \\
\hline 5 & 6320 & 4920 & 3426 & 2640 & 3010 & 2900 & 3256 & 2699 & 3893 & 2956 & 3002 \\
\hline 6 & 4890 & 6855 & 3987 & 2800 & 3500 & 3162 & 3450 & 2400 & 4563 & 2899 & 3209 \\
\hline 7 & 6450 & 7956 & 2859 & 3246 & 3254 & 3098 & 3456 & 3411 & 4633 & 3697 & 3505 \\
\hline 8 & 7140 & 9546 & 4270 & 3671 & 3517 & 3245 & 3366 & 3718 & 5526 & 4471 & 4039 \\
\hline
\end{tabular}




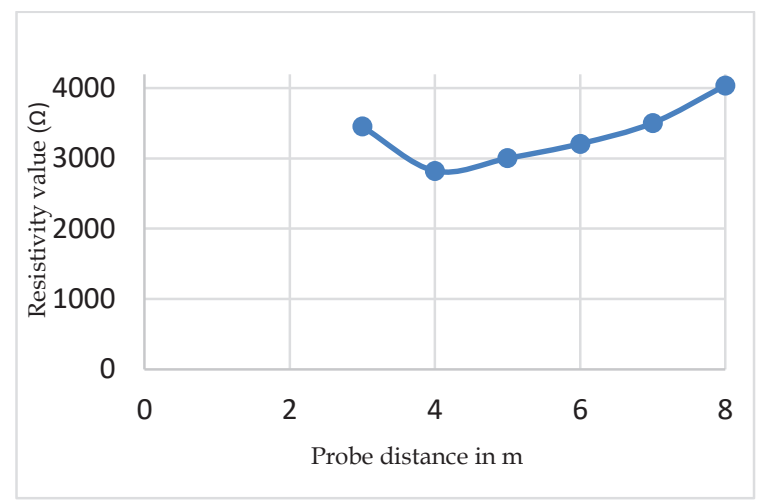

Figure 3 - Resistivity variation with probe space

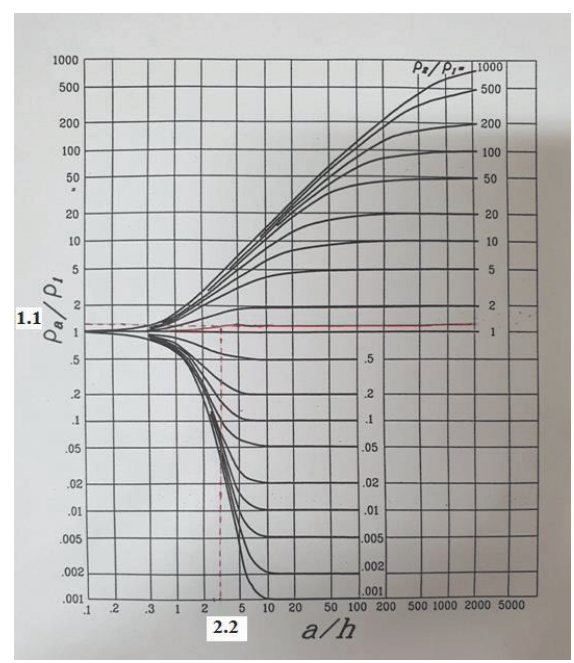

Figure 4 - Sunde's graph

Using average resistivity values calculated in Table 1 and relevant probe spaces, Figure 3 was plotted. Thereafter, top layer resistivity value $\left(\rho_{1}\right)$ and bottom layer resistivity value $\left(\rho_{2}\right)$ were selected by using Figure 4 and further process of modelling of two-layer soil model was prepared as described below [5].

Selected $\rho_{1}$ and $\rho_{2}$ value from Figure 3, Upper layer resistivity $\left(\rho_{1}\right)=3450 \Omega \mathrm{m}$ Lower layer resistivity $\left(\rho_{2}\right)=4000 \Omega \mathrm{m}$ Selected $\rho_{2} / \rho_{1} \quad=1.16$

From Sunde's graph, Figure 4

Selected $\rho_{a} / \rho_{1}$

$$
=1.1
$$

Selected $\mathrm{a} / \mathrm{h}=2.2$

$\rho_{1}=1.1 \times 3454=3799 \Omega \mathrm{m}$

Probe space at $3799 \Omega \mathrm{m}$ resistivity value (from Figure 3) $=7.9 \mathrm{~m}$

Upper layer depth $(\mathrm{h})=7.9 / 2.2=3.6 \mathrm{~m}$

\subsection{Discrete Soil Resistivity Model}

Actual 3D image of the BHP switchyard can be modelled using interpolation technique and measured resistivity values. Resistivity survey was conducted to collect the resistivity value of
$50 \mathrm{~m} \times 45 \mathrm{~m}$ BHP switchyard. Using the surface resistivity values, soil resistivity profile of the surface of BHP switchyard can be plotted as shown in Figures 5 and 6, respectively.

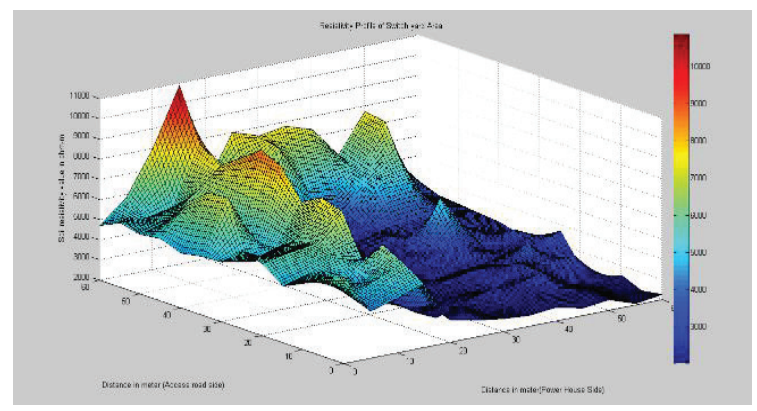

Figure 5 - Resistivity profile of the BHP switchyard

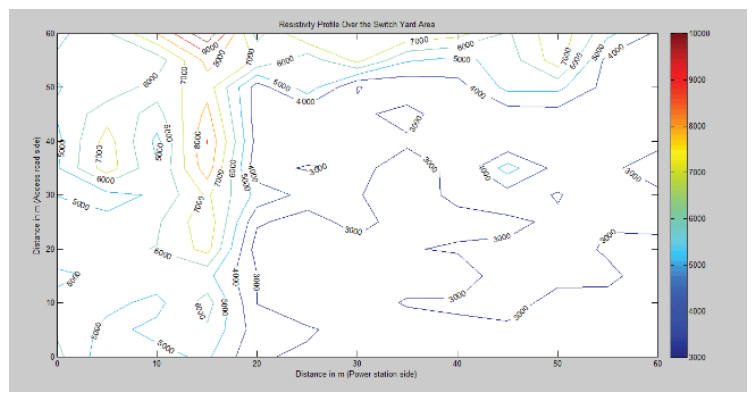

Figure 6 - Contour plot of the resistivity profile

\section{Grounding System Design}

\subsection{Grid design based on IEEE 80-2000 standard}

\section{Basic Design Parameters}

$\begin{array}{lcc}\text { Fault Current }(\mathrm{kA})[4] & \boldsymbol{I} & 22 \\ \text { Fault clearing time }(S) & \boldsymbol{t}_{\boldsymbol{C}} & 0.5 \\ \text { Maximum allowable temperature }\left({ }^{\circ} \mathrm{C}\right) & T_{m} & 350 \\ \text { Ambient temperature }\left({ }^{\circ} \mathrm{C}\right) & T_{\boldsymbol{a}} & 30 \\ \text { Material constant for copper } & \boldsymbol{K}_{\boldsymbol{0}} & 242 \\ \begin{array}{l}\text { Thermal capacity factor for copper } \\ \left(\mathrm{J} / \mathrm{cm}^{30} \mathrm{C}\right)\end{array} & T C A P & 3.42 \\ \begin{array}{l}\text { Thermal coefficient of resistivity for } \\ \text { copper }\end{array} & \boldsymbol{a}_{r} & 0.0038 \\ \begin{array}{l}\text { Specific resistivity for copper }(\Omega m) \\ \boldsymbol{\rho}_{r}\end{array} & 1.78 \\ \begin{array}{l}\text { Resistivity of surface layer }(\mathrm{crushed} \\ \text { rock) }(\Omega m)\end{array} & \boldsymbol{\rho}_{s} & 45000 \\ \text { Shock time (s) } & \boldsymbol{t}_{s} & 0.5 \\ \text { Soil resistivity }(\Omega m) & \boldsymbol{\rho} & 3799 \\ \text { Thickness of surface layer }(m) & \boldsymbol{h}_{s} & 0.1\end{array}$


Calculation of conductor sizing for short time thermal requirements

Required conductor size as a function of conductor current can be obtained using equation 37 in IEEE 80-2000 standard [5] and calculated conductor cross section value $(A)$ was $85.1 \mathrm{~mm}^{2}$. Therefore, copper conductor of $100 \mathrm{~mm}^{2}$ cross section was selected as final conductor size.

Calculation of tolerable step and touch voltage

Maximum driving voltages of human body at any accidental cause should not exceed the maximum allowable step and touch voltage limits which can be calculated using equation $29,30,32$, and 33 in IEEE 80-2000 standard [5]. Hence calculated tolerable touch voltages and step voltages for particular conditions of $50 \mathrm{~kg}$ and $70 \mathrm{~kg}$ persons respectively are as given in Table 2.

Table 2 - Tolerable touch \& step voltages

\begin{tabular}{|c|c|c|}
\hline \multirow{2}{*}{$\begin{array}{c}\text { Parameter } \\
\text { (Volts) }\end{array}$} & \multicolumn{2}{|c|}{ Resistivity of surface material } \\
\hline & $\begin{array}{c}10000 \Omega \mathrm{m} \\
\text { (crush rock) }\end{array}$ & $\begin{array}{c}45000 \Omega \mathrm{m} \\
\text { (asphalt) }\end{array}$ \\
\hline E_touch_50 & 2155 & 8090 \\
\hline E_touch_70 & 2916 & 10949 \\
\hline E_step_50 & 8128 & 31869 \\
\hline E_step_70 & 11001 & 43133 \\
\hline
\end{tabular}

Calculation of $I_{g}$ (single phase to earth fault current) For the calculation of single phase to earth fault current $I_{g}$, appropriate zero sequence current $\mathrm{I}_{0}$ during single line-to-ground fault is required and $I_{g}$ can be calculated using equation 69 in IEEE 80-2000 standard [5]. Calculated single phase to earth fault current was 12.6kA.

\section{Calculation of split factor}

To calculate the split factor, remote contribution and the local contribution of the fault current are required. According to IEEE 80-2000 standard, four different types of contributions such as $100 \%$ remote, $25 \%$ local $75 \%$ remote, $50 \%$ local $50 \%$ remote, $75 \%$ local $25 \%$ remote are discussed, and graphical analyse method is used for this calculation. Earth resistance of a transmission line tower earthing system was taken as $15 \Omega$. Finally, worse case value of $56 \%$ was selected as final split factor [5].

Calculation of decrement factor

Decrement factor $\mathrm{D}_{f}$, was derived to take into account the effect of DC current offset. Table 10 given in the IEEE 80-2000 standard was used to calculate the decrement factor. $\mathrm{X} / \mathrm{R}$ ratio and fault duration were taken as 10 and $0.5 \mathrm{~s}$ respectively for this calculation and based on which the selected decrement factor was 1.026.

\section{Calculation of grid current}

Using the calculated values of split factor, single phase to ground fault current and decrement factor, computed grid current was found to be $7.24 \mathrm{kA}$.

\section{Calculation of grid resistance}

To calculate the grid resistance, equation 52 of IEEE 80-2000 standard can be used. For this purpose, the area of the grid, soil resistivity and total conductor length are required. Total conductor length is the sum of horizontal conductor lengths and total earth rod lengths. This depends on the space factor of the horizontal conductors. For this calculation, value of soil resistivity and area of BHP switchyard were required and those were taken as $3799 \Omega \mathrm{m}$ and $2250 \mathrm{~m}^{2}$, respectively. Calculated grid resistance for $5 \mathrm{~m} \times 5 \mathrm{~m}$ mesh size was $37.98 \Omega$ and resultant ground potential rise was found to be $274975 \mathrm{~V}$. According to IEEE standard, this value is not satisfying the step and touch voltage criteria mentioned in the regulation. Hence possible alternative methods should be analysed to reduce the grid resistance [12].

\subsection{Design of earthing system based on FEM}

\subsubsection{Development of a mathematical model to calculate surface voltage distribution}

According to the given description of the FEM modelling under methodology section, leakage current owing to fault current passes throughout the entire region as shown below in Figure 7. Here, 2D layer of soil region was considered only for explanation purpose only. Kirchhoff's current and voltage law were applied for each and every small soil element in 2D soil layer considered to be small resistances connected to each other as shown below.

Applying Kirchhoff's current law for the elements connected to node 11 :

$$
\begin{gathered}
(V 11-V 12) / R_{11-12}+(V 11-V 15) / R_{11-15}+(V 11-V 10) / \\
R_{11-10}+(V 11-V 7) / R_{11-7}=I_{g} \\
-\left[1 / R_{11-15}\right] V 15-\left[1 / R_{11-12}\right] V 12-\left[1 / R_{11-10}\right] V 10- \\
{\left[1 / R_{11-7}\right] V 7+\left[1 / R_{11-12}+1 / R_{11-15}+1 / R_{11-10}+1 /\right.} \\
\left.R_{11-7}\right] V 11=I_{g}
\end{gathered}
$$

This can be written as

$$
-a_{11} V 15-b_{11} V 12-c{ }_{11} V 10-d_{11} V 7+e_{11} V 11=I_{g}
$$



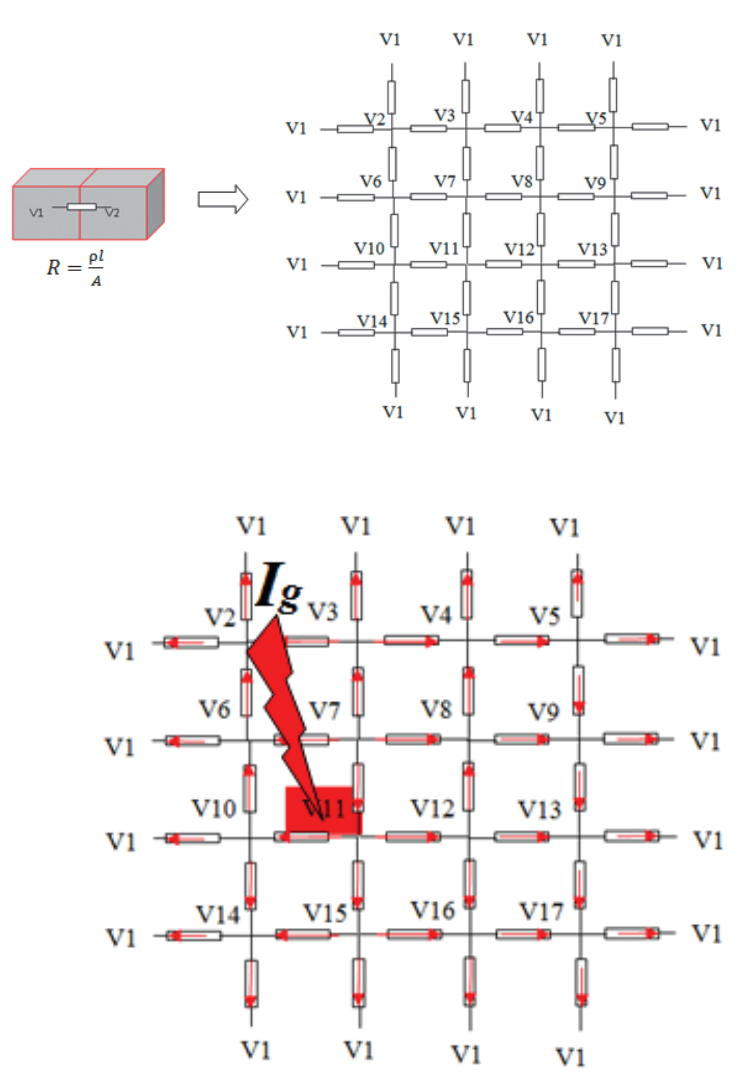

Figure 7 - Building mathematical model for surface voltage distribution

Likewise, sixteen linear equations can be written by applying Kirchhoff's current law for the elements connected to node 2 to node 17.
For V2
$a_{2} V 2-b_{2} V 3-c_{2} V 6=0$
For V3$$
a_{3} V 3-b_{3} V 2-c{ }_{3} V 4-d_{3} V 7=0
$$

For V16 $a_{16} V 16-b_{16} V 12-c_{16} V 15-d_{16}$ For V17 $a_{17} V 17-b_{17} V 13-c_{17} V 16=0$ etc.

Thereafter the following matrix can be established and re-arranged using above 16 equations.

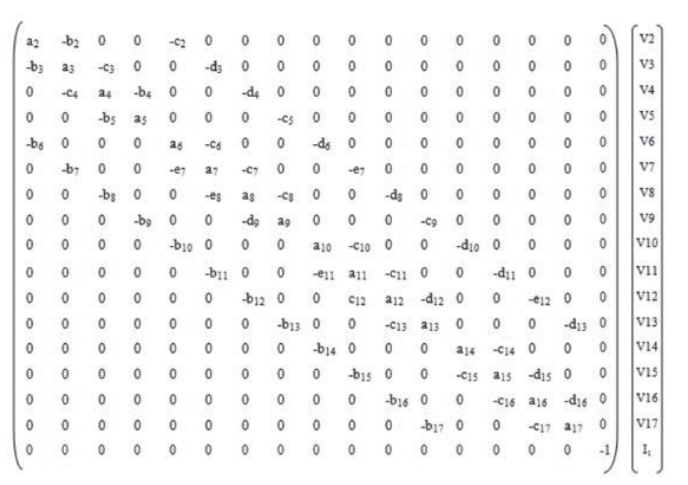

[Matrix_A] [Matrix_B] = [Matrix_C]
Hence, unknown voltages of these equations can be found by solving this matrix.

\subsubsection{Earthing system of BHP switchyard using FEM model}

Under simulation of FEM modelling, surface voltage distribution of earthing system, which consists of $3 \mathrm{~m}$ in length of 38 earth rods along the perimeter and earth conductors of $5 \mathrm{~m} \times 5$ $\mathrm{m}$ mesh, was simulated applying grid current of 7239 A. For this simulation, MATLAB coding was used.

Since the actual earthing system is spread over $45 \mathrm{~m} \times 50 \mathrm{~m}$ area, resistivity values of $60 \mathrm{~m} \times 55$ $\mathrm{m} \times 8 \mathrm{~m}$ soil region were used for discrete soil resistivity modelling, because the effect of the boundary region can be emphasized by extending the soil region. Figure 8 shows the surface voltage distribution of the FEM simulation with cubic element size $1 \times 1 \times 1 \mathrm{~m}$.

Smaller element size produces more accurate results, but it requires high computer RAM capacity. Variation of the model accuracy with the element size is discussed under Appendix C. According to model verification, cubic element size of $0.053 \mathrm{~m} \times 0.053 \mathrm{~m} \times 0.053 \mathrm{~m}$ produces the best result of FEM modelling.

FEM Model simulated ground potential rise (GPR) of the earth grid is $57730 \mathrm{~V}$ (Calculated GPR using the conventional method was $274975 \mathrm{~V})$, which is much higher than the tolerable touch voltage of $8090 \mathrm{~V}$.

Grid resistance $7.974 \Omega$ was calculated by dividing GPR from grid current. Since the simulated grid resistance and GPR is higher than the IEEE safe limits, initial design of earth grid was not recommended. Touch voltage distribution also violates the tolerable limits specified by IEEE regulation as shown in Figures 8 and 9.

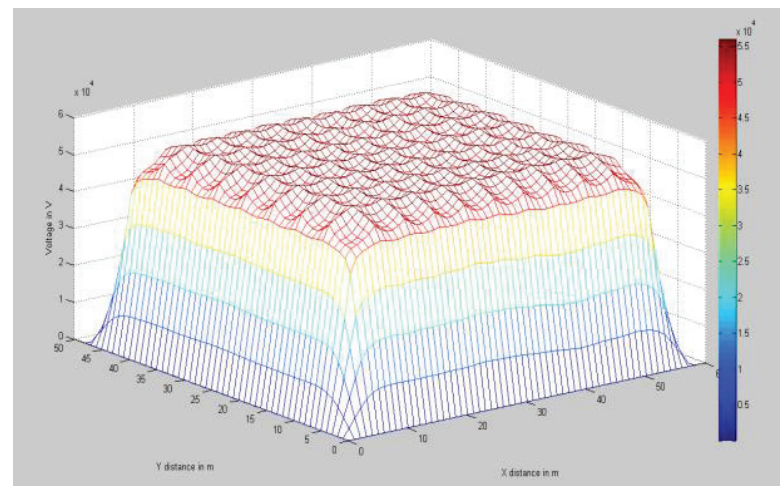

Figure 8 - Surface voltage distribution of BHP switchyard 


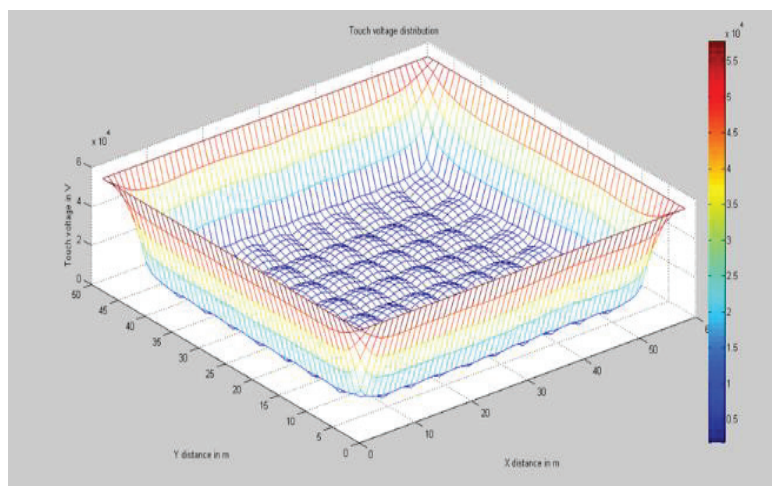

Figure 9 - Touch voltage distribution of BHP switchyard

\section{Sensitivity Analysis}

It was observed as per the results obtained in the previous sections that grid resistance of the switchyard was not falling within the acceptable range with conventional earthing designs. Owing to the limitation of the grid area for expansion, further reduction of the grid earth resistance was also not possible. Therefore, following alternatives were considered to reduce the grid resistance to a standard acceptable value [6][13].

1. Connecting another grid in parallel which has a low resistance value [14].

2. Changing the driven rod diameter or its cross section [7].

3. Changing the earthing grid conductor cross section and its length [7].

4. Refilling the switchyard area with low resistivity soil [8].

\subsection{Connecting the concrete encased tailrace grid}

Concrete, being hygroscopic, attracts moisture. Concrete block buried in soil behaves as a semiconducting medium with a resistivity of 30-90 $\Omega \mathrm{m}$. This can be taken as better grounding medium rather than higher resistivity soil region in earthing design [5][13]. Typical values used for the computation of parallel grid resistance were: $5 \mathrm{~m}$ rod length, $120 \Omega \mathrm{m}$ wet concrete resistivity, $0.2 \mathrm{~m}$ buried depth (h) and $5 \mathrm{~m}$ length rods buried around perimeter.

Grid resistance and total conductor length variation against switchyard area are as shown in Figures 10 \& 11, respectively. Using these graphs, mesh size of $12.5 \mathrm{~m} \times 10 \mathrm{~m}$ was selected as the most economical mesh size. Thereafter the combined grid resistance is computed as described below. As can be seen, it would reach the desired value after increasing the tailrace area up to $3250 \mathrm{~m}^{2}$ [13][14].

$[1 /$ combined grid resistance $]=[1 /$ switchyard earth grid resistance $]+[1 /$ tail race earth grid resistance]

$[1 /$ Combined grid resistance $]=[1 / 37.98]+$

Combined grid resistance $\quad=1.041 \Omega$

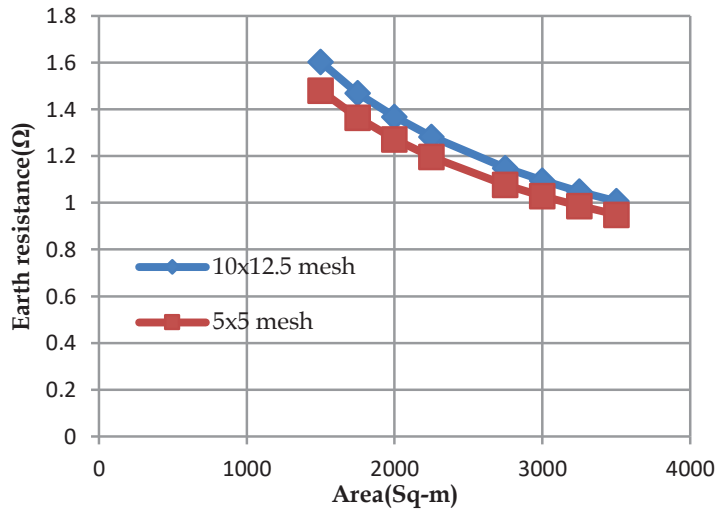

Figure 10 - Variation of grid resistance with grid area

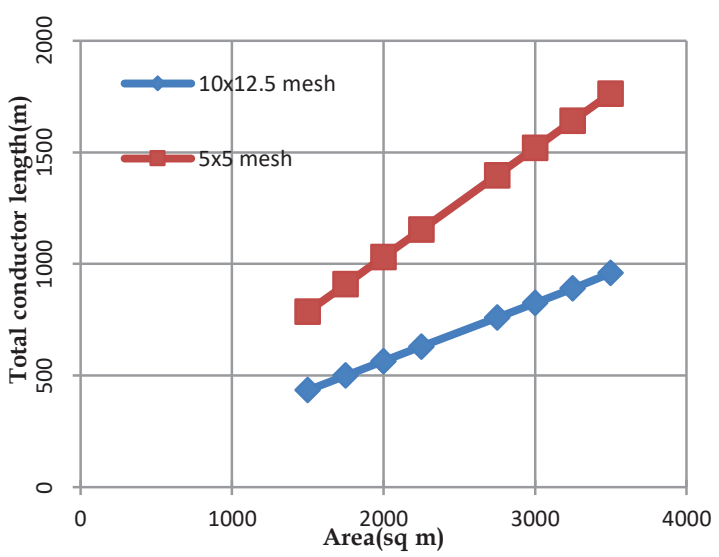

Figure 11 - Variation of total conductor length with grid area

\section{Calculation of Ground Potential Rise}

Ground potential rise depends on the passing grid current through the earth grid. With the combined grid arrangement, larger portion of the grid current passes through the satellite grid and lesser part of the same would pass through the main grid. Calculated ground potential rise was found to be $7596 \mathrm{~V}$ which is lower than the tolerable touch voltage $8090 \mathrm{~V}$. Also, it can be seen that the design value is satisfying the IEEE standard condition when the surface layer material of $\rho_{\mathrm{s}}=45000 \Omega \mathrm{m}$ is used since the tolerable touch voltage of switchyard with $10,000 \Omega \mathrm{m}$ surface material is $2,155 \mathrm{~V}$. 
6.2 Variation of grid resistance with rod diameter

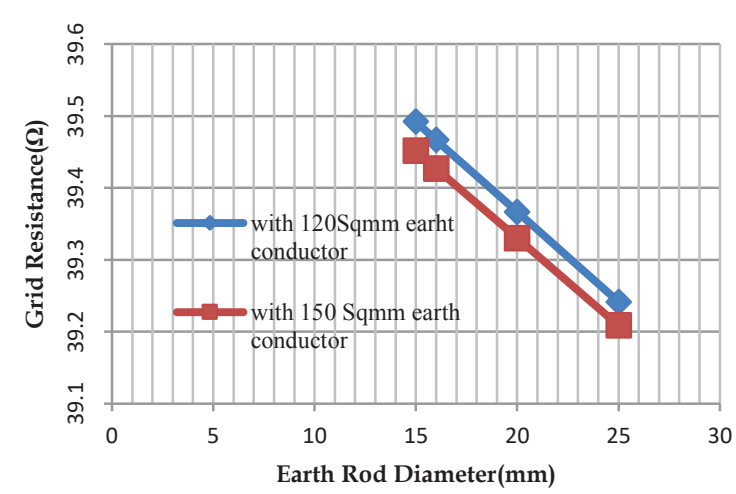

Figure 12 - Variation of grid resistance with rod diameter

Figure 12 shows the variation of grid resistance against the rod diameter as per the calculation performed according to the Schwarz's equation. It can be seen from the graph that the earth resistance doesn't show any significant variation on rod diameter size. Hence, change in rod diameter does not influence much in reducing the earth resistance [7].

\subsection{Variation of grid resistance with mesh} conductor cross section and its length

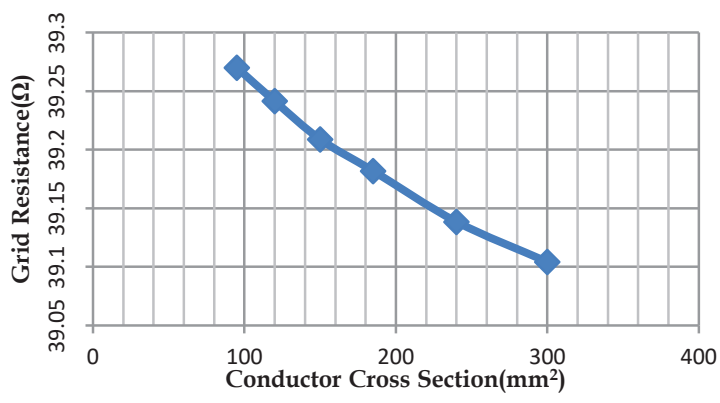

Figure 13 - Variation of grid resistance with mesh conductor cross section

As can be seen from Figure 13, selection of earthing conductor having a large cross section area doesn't give any considerable reduction in earth resistance. Hence, this alternative too cannot be used as a possible option to reduce grid resistance.

Total conductor length directly depends on the mesh size of the earth grid and the potential distribution of the switchyard depends on the mesh size. However, when the mesh size is reduced, potential distribution of the switchyard tends to distribute smoothly even though the earth resistance is not reduced by a considerable amount. Variation of grid resistances with mesh conductor length for various mesh sizes is shown in Figure 14.

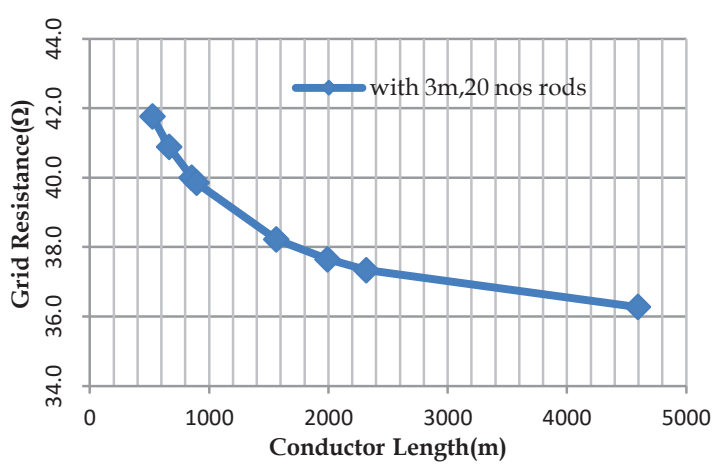

Figure 14 - Variation of grid resistance with mesh conductor length

As can be seen, the reduction of grid resistance below $1 \Omega$ is not possible by decreasing the mesh sizes [7].

\subsection{Soil treatment by backfilling the contact surface of the electrodes}

Under this option, critical resistance region [9][10] of the grounding system was replaced by $\quad 90-110 \Omega \mathrm{m}$ low resistivity material [11]. Critical resistance region of $56 \mathrm{~m} \times 51 \mathrm{~m} \times 3.8 \mathrm{~m}$ is shown in the following Figure 15.

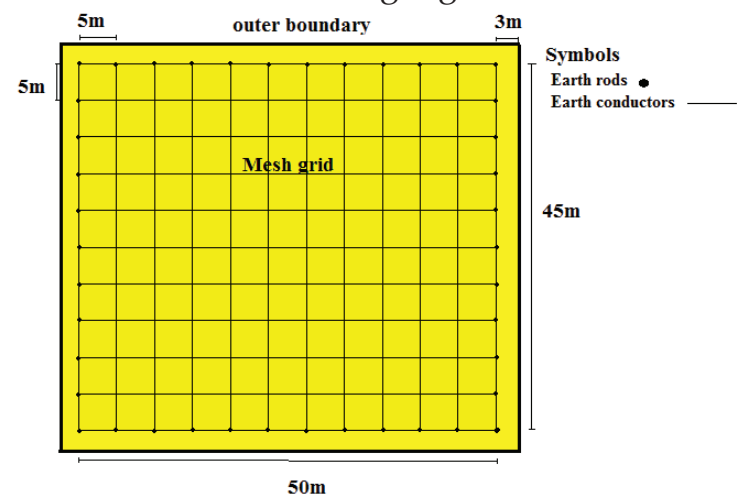

Figure 15 - Critical resistance region of the BHP switchyard

After replacing soil in critical resistance region, following earth resistance values were obtained using Schwarz's equations [7].

$R_{1}=1.02 \Omega \quad R_{2}=1.43 \Omega \quad R_{m}=0.94 \Omega \quad R_{g}=1.01 \Omega$ Where:

$R_{1}=$ Ground resistance of grid conductors

$R_{2}=$ Ground resistance of all ground rods

$R_{m}=$ mutual ground resistance between the group of grid conductors and group of ground rods

$R_{g}=$ Total system resistance

Therefore, further improvement need not be necessary to enhance the design. Hence,

GPR $=7239 \times 1.01<8090$ V(E_touch_50) 
To maintain the tolerable higher touch potential value of $8090 \mathrm{~V}$, surface layer material of asphalt with $\rho_{\mathrm{s}}=45000 \Omega \mathrm{m}$ has to be used to satisfy the IEEE requirement.

\subsection{Simulation of soil backfilling using FEM} model

FEM model can be used to analyse the behaviour of surface voltage distribution after soil backfilling. Following figures illustrate the surface voltage distribution under different soil backfilling conditions.

Surface voltage distribution before refilling

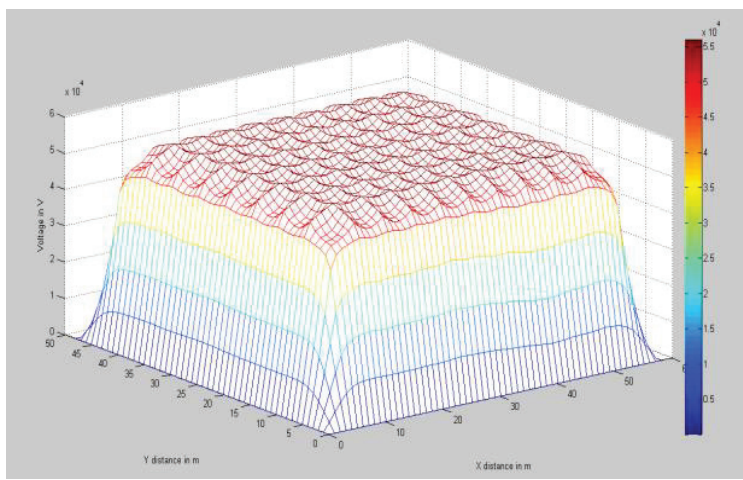

Figure 16 - Surface voltage distribution before backfilling

Surface voltage distribution after refilling of $3.8 \mathrm{~m}$ height topsoil layer with

$100 \Omega m$ soil- 5 m $x 5$ m mesh

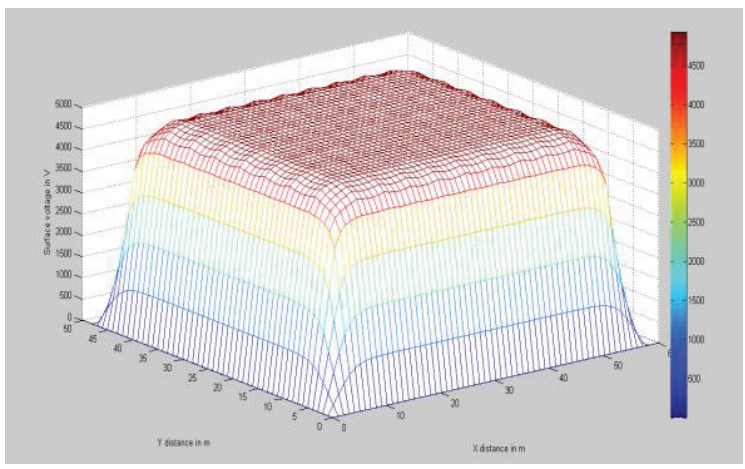

Figure 17 - Surface voltage distribution after the replacement of topsoil layer by $3.8 \mathrm{~m}$

After replacing the $3.8 \mathrm{~m}$ topsoil layer, ground potential rise (GPR) of the earth grid is found to be $4932 \mathrm{~V}$, which is lower than the tolerable touch voltage of $8090 \mathrm{~V}$.

$$
\text { Grid resistance }=\frac{4932}{7239}=0.6813 \Omega
$$

Surface voltage distribution after refilling of $3.8 \mathrm{~m}$ height topsoil layer with $100 \Omega \mathrm{m}$

Soil with $10 m \times 11.5 \mathrm{~m}$ mesh

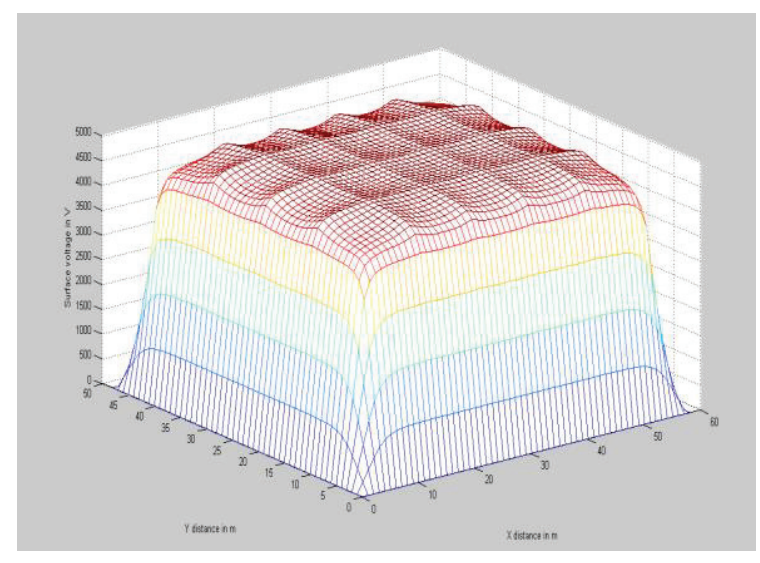

Figure 18 - Surface voltage distribution after the replacement of topsoil layer by $3.8 \mathrm{~m}$ with $10 \mathrm{~m} \times 11.5 \mathrm{~m}$ mesh

After changing the mesh size, GPR of the earth grid was found to be $4932 \mathrm{~V}$, which is lower than the tolerable touch voltage of $8090 \mathrm{~V}$. Accuracy of results of the simulation can be increased with the selection of smaller element size. However, the value exceeds the tolerable touch value since the difference between GPR and the tolerable touch value is relatively high. Comparison of GPR values between discussed alternative solutions are illustrated in Table 3.

Table 3 - Comparison of GPR values

\begin{tabular}{|c|c|c|c|}
\hline \multirow{2}{*}{ Description } & \multicolumn{3}{|c|}{ GPR value (V) } \\
\cline { 2 - 4 } & $\begin{array}{c}\text { Initial } \\
\text { design }\end{array}$ & $\begin{array}{c}\text { Connecting } \\
\text { to tailrace }\end{array}$ & $\begin{array}{c}\text { Soil } \\
\text { backfilling }\end{array}$ \\
\hline $\begin{array}{c}\text { Conventional } \\
\text { method }\end{array}$ & 274975 & 7535 & 7311 \\
\hline FEM model & 57730 & N/A & 4939 \\
\hline & & 8090 & 7810 \\
\hline $\begin{array}{c}\text { Tolerable touch } \\
\text { voltage }\end{array}$ & 8090 & & \\
\hline
\end{tabular}

Grid resistance $=\frac{4932}{7239}=0.6813 \Omega$

Touch potential distribution plotted in Figure 19 shows that the maximum potential is lower than the tolerable touch potential $8090 \mathrm{~V}$.

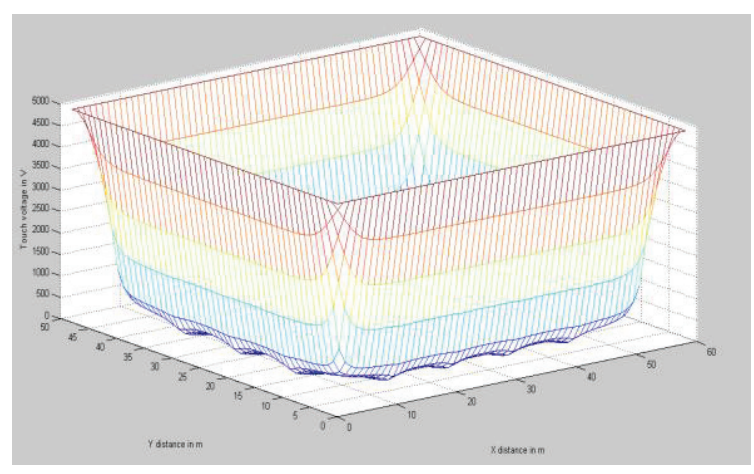

Figure 19 - Touch potential distribution after $3.8 \mathrm{~m}$ soil layer replacement 
Step potential distribution of a person when moves along the $\mathrm{X}$-direction and $\mathrm{Y}$-direction are shown in Figures 20 and 21, respectively. It can be observed that the maximum step potential is lower than the tolerable step voltage $31869 \mathrm{~V}$.

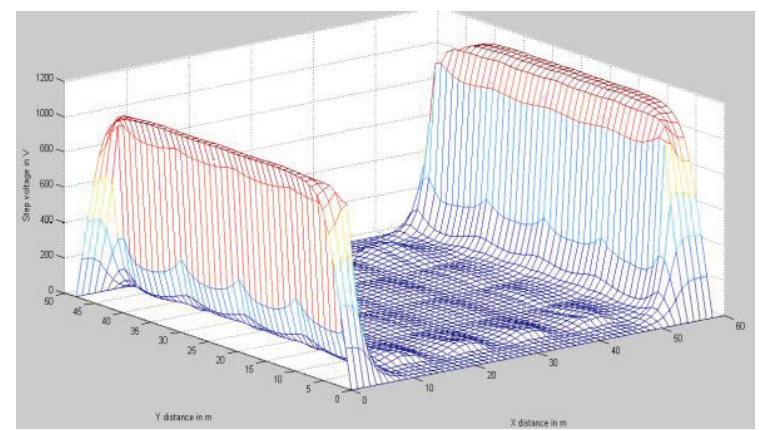

Figure 20 - Step voltage distribution along $X$ direction after the replacement of topsoil layer by $3.8 \mathrm{~m}$

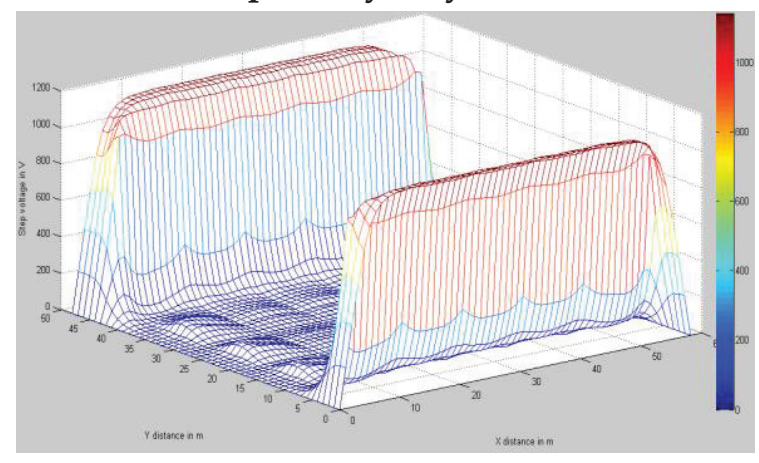

Figure 21 - Step voltage distribution along $\mathrm{Y}$ direction the replacement of topsoil layer by $3.8 \mathrm{~m}$

Therefore, backfilling of $3.8 \mathrm{~m}$ topsoil layer with $90-110 \Omega \mathrm{m}$ soil and high resistivity surface layer material of asphalt $(45000 \Omega \mathrm{m})$ as surface layer material is recommended to maintain higher tolerable touch potential value.

\section{Validation of FEM Model}

Accuracy or the sensitivity level of analytical capabilities of the parameters such as surface voltage distribution, touch voltage distribution, step voltage distribution, GPR calculation and grid resistance $\left(R_{g}\right)$ calculation depends on the size of the finite soil element. Minimizing of soil element size tremendously increases the requirement of computer RAM capacity. As such, the minimum requirement for $1 \mathrm{~m} \times 1 \mathrm{~m} \times 1 \mathrm{~m}$ element size simulation requires minimum of 8 GB RAM capacity. Therefore, better accuracy can be reached by reducing the element size as described in Appendix C, Figure C1 \& Figure C2 respectively.

\section{Research observations in summary}

This research study focused on the design and assessment of switchyard grounding system of Broadlands hydropower station. Initially, two soil models were prepared based on the soil resistivity survey results of the area concerned. The first model was based on the guidelines of IEEE 80:2000 standards (Sunde's graphical method) and the second was a discrete soil resistivity model. Observed apparent resistivity value of soil from the former method was $3,799 \Omega \mathrm{m}$. Based on the results of soil resistivity survey, the design of earth grid was conducted for the whole switchyard area using two techniques based on, namely,

- Guidelines of IEEE 80:2000 standards

- Discrete finite element method

Post analysis of ground potential rise and touch potential of the initial grid design revealed that some boundary spot values are exceeding the standard limits. As a result, study extended to investigate the possible remedial measures which can make the critical values to lie within acceptable safe limits. Four remedial options were considered, and they are:

- Connecting the switchyard earth grid to the tailrace grid

- Changing the earth driven rod diameter

- Changing the grid conductor cross section \& mesh size

- Effective refilling of soil with high conductive material

\section{Conclusion and Recommendations}

Based on the results and observations of the research, following conclusions and recommendations are prepared.

1. Owing to the high soil resistivity, the basic design of BHP switchyard itself is not safer under worst case fault analysis i.e. exceeding the safe permissible limits of step and touch potentials. Since the switchyard is located close to the public access roads, proper design with a high safe margin is essential.

2. Further, expansion of the switchyard grid is not possible owing to insufficient land area. However, connecting to a separate satellite grid option is possible at a high cost.

3. Paralleling the switchyard grid with existing tailrace grid made the effective resistance significantly lower, nevertheless not reaching the required acceptable level of earth resistance $(<1 \Omega)$. However, approximately about $3250 \mathrm{~m}^{2}$ tailrace grid 
network is required to lower the effective earth resistance less than $1 \Omega$.

4. No significant improvement of earth resistance is possible with the increase of rod electrode cross section.

5. Increasing the cross section of the earth mesh conductors does not have considerable impact on lowering the earth resistance.

6. Total length of the earth grid conductors or miniaturizing the grid mesh size does not have significant impact on lowering the earth resistance too.

7. The most suitable optimum grid mesh size is $10 \mathrm{~m} \times 11.5 \mathrm{~m}$ and the economical buried length of the rod electrode is $3 \mathrm{~m}$. It was also found that the near surface soil resistivity is highly effective for maintaining the required tolerable step and touch potential levels and recommended to fill up with $45000 \Omega \mathrm{m}$ high resistivity soil for about $10 \mathrm{~cm}$ thickness or more.

8. Replacing the high resistivity soil in the bottom layer with low resistivity material of $90-110 \Omega \mathrm{m}$ is preferable thus reducing the total effective earth resistance of the BHP switchyard to permissible value.

9. FEM model built up using MATLAB found highly effective in the micro analysis of the discrete soil resistivity modelling and distributed parameter analysis of earth system.

In summary, this research study concludes and recommends that the most suitable earth grid arrangement for the switchyard of Broadlands hydropower project should be a combined treatment of items $7 \& 8$ mentioned above.

\section{Acknowledgement}

The authors would like to offer their appreciation to Eng. (Dr.) L. B. K. Laksiri, Project Director of BHP (CEB), for granting permission to proceed with this study, and Eng. (Dr.) Narendra de Silva of LECO for his assistance throughout this endeavour.

\section{References}

1. He, J., Rong, J. H., Zeng, Z., Methodology and technology for power system grounding, $1^{\text {st }}$ edition., Wiley, Singapore,2013, pp.81-270

2. China Hunan Hydro and Power Design Institute, \& China National Electric Engineering Co. Ltd, Basic Design Report of Sri Lanka Broadlands Hydropower Project, March, 2014
3. Substations Committee, IEEE Guide for Measuring Earth Resistivity IEEE Std 80-2012, Ground Impedance, and Earth Surface Potentials of Grounding System, IEEE Power and Energy Society, USA, Revision of IEEE Std 81-1983, December,2012, pp. 30-36.

4. Transmission planning branch of CEB, "Longterm Transmission Development Plan 20182027", 2019.

5. Substation Committee, IEEE Guide for Safety in AC Substation Grounding IEEE Std 80-2000, IEEE Power Engineering Society, USA, Revision of IEEE Std 80-1986, January, 2000, pp. 3-95.

6. Narayanan, M. M. B., Sarkar, B. N., Prabhakar, C., \& Mishra, S.C., "Design of Grounding System for Tehri Hydro Power Project", NPSC, 2002, pp.98-99.

7. Schwarz, S. J., "Analytical Expressions for the Resistance or Grounding Systems", IEEE Transaction on Power Apparatus and System, Vol. 73, No 2, Jan, 1954, pp. 1011-1015.

8. Okyere, P. Y., Eduful, G., "Reducing Earth Electrode Resistance by Replacing Soil in Critical Resistance Area", IJME, Vol. 6, No. 2, spring, 2006

9. Arainy, A. A., Khan, Y., Qureshi, M. I., Malik, M. H., \& Pazheri, F. R., “Optimized Pit Configuration for Efficient Grounding of the Power System in High Resistivity Soils using Low Resistivity Materials", ICMSAO, April 2011

10. Eduful, G., Cole, J. E., \& Okyere, P. Y., “Optimum Mix of Ground Electrodes and Conductive Backfills to Achieve a Low Ground Resistance", WCECS, Vol. 1, Oct, 2009, pp. 978-988

11. Manikandan, M., "Characterization and Comparison Studies of Ben tonite and Fly ash for Electrical Grounding" , ICECCT, 2015, 3p

12. Ackerman, A., \& Sen, P. K., "Designing Safe and Reliable Grounding in AC Substations with Poor Soil Resistivity: An Interpretation of IEEE Std. 80", IEEE Transaction on Industry Applications, Vol. 49, No. 4, July 2013, pp.1883-1888

13. Arora, J. K., \& Seedher, H. Grounding system design for an underground hydro-electric plant a case study", TENCON, 1991, pp. 467-471.

14. https://www.goaelectricity.gov.in/Regulations/ OM/\%2065B\%20Earthing\%20practices\%20Addi tional.doc, Visited, 23 rd Aug 201 


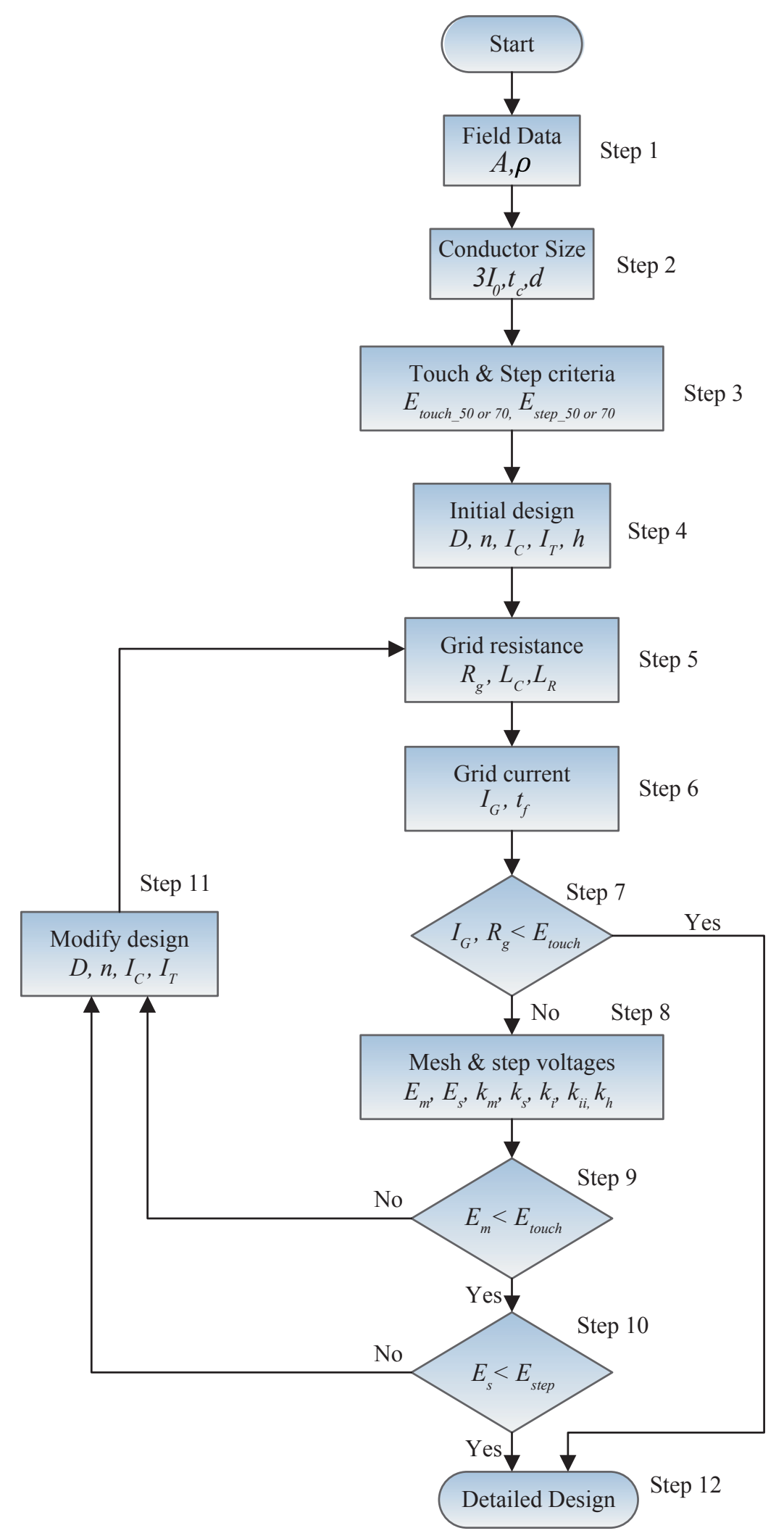

Figure A1 - Flow chart of earthing design according to IEEE 80:2000 


\section{Appendix -B - Flow chart of FEM model}

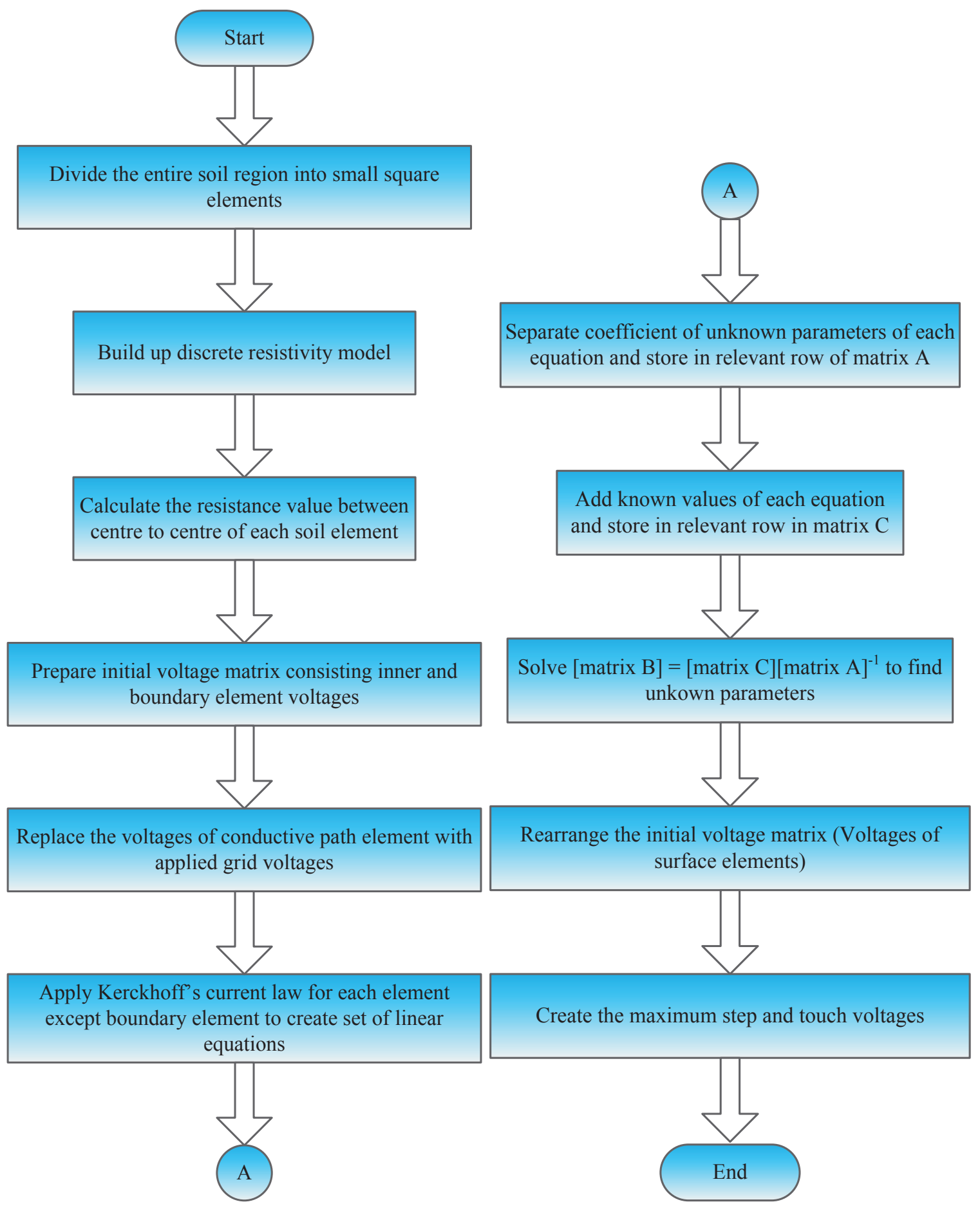

Figure B1 - Flow chart of FEM model 


\section{Appendix - C Validation of FEM model}

Apparent resistance given by an earth rod buried in the soil is calculated by the following equation

Where:

$$
R=\frac{\rho}{6.285 l} \ln \frac{(r+l)}{r}
$$

$\rho$ is resistivity of soil

$l$ is length of earth rod

$r$ is radius of the rod

Earth resistance of a rod electrode of $3 \mathrm{~m}$ length and $25 \mathrm{~mm}$ diameter buried in the soil resistivity of $3799 \Omega \mathrm{m}$ is,

$R=\frac{3799}{6.285 * 3} \ln \frac{(0.0125+3)}{0.0125} \quad R=1105 \Omega$

But in reality, discrete FEM model treats all the soil and conductor parts as elements and therefore limited satisfactory is acceptable in fair comparison for both methods. The basis was prepared on sphere of influence concept to be used in FEM and the basic model comparison concept is illustrated below.

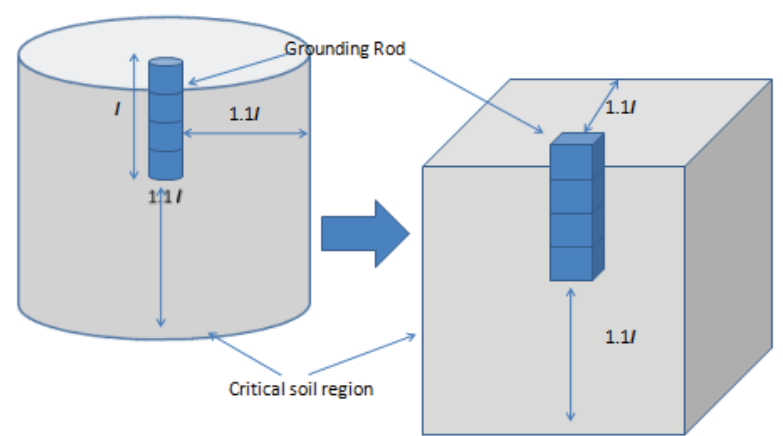

Figure C1 - Conversion of Critical resistance region of single rod to FEM model

The practical satisfactory values for the elements of discrete FEM model were identified as $1 \mathrm{~m}, 0.5 \mathrm{~m}$, $0.25 \mathrm{~m}$ and $0.2 \mathrm{~m}$. Calculation of smaller element capacities was curtailed due to computer RAM capacity. Therefore, comparison had been done in equal flat form by making all parameters kept the same for both cases. The results are given below in Figure C2.

Equation calculated $R_{g}$ Vs model calculated $R_{g}$

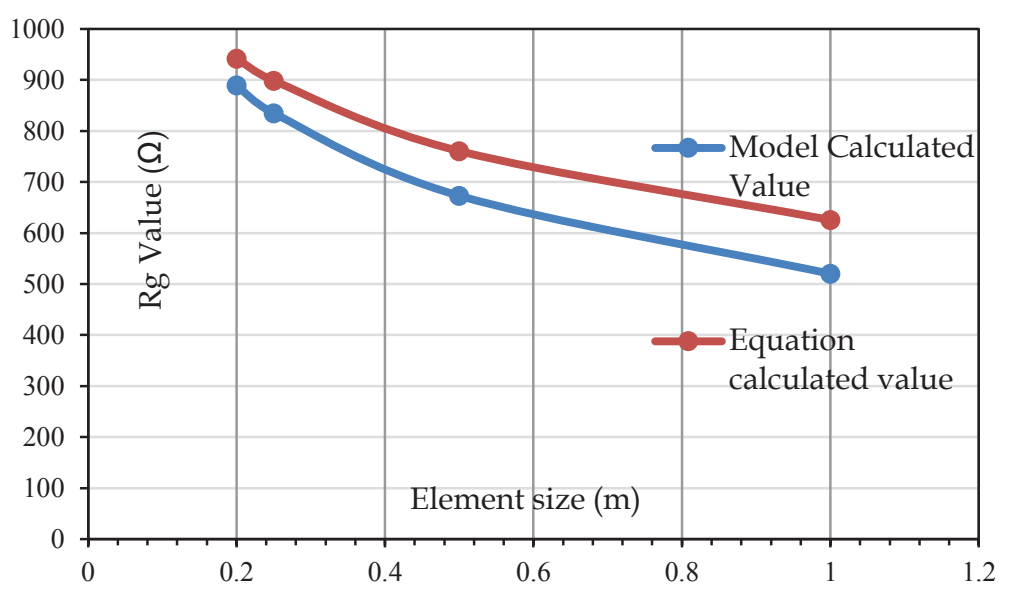

Figure C2 - Comparison of Equation Vs Model calculated $\boldsymbol{R}_{g}$ values

It was clearly evident that results of the two models follow a similar pattern. Also, smaller the element size, less error generated between the two methods. This was a significant result to validate the discrete model and, as a result, mathematical analysis conducted to further ascertain this phenomenon. Best fit line for the given points were well matched to $3^{\text {rd }}$ order polynomial claiming for best theoretical regression fit line. According to the forecast, optimum results will reach around element size of $0.053 \mathrm{~m}$ or $53 \mathrm{~mm}$. 